\title{
Constructive Exploration of Transforming STEM Library Group Study Room into Individual Study Room
}

\author{
Yueru He \\ University of Maryland Math Major Undergraduate
}

Keywords: STEM Library; Learning Environment; Soundproof Wall; Individual Study Room

\begin{abstract}
In recent years, with more and more faculties and students in school, the university has seen a growing demand for access to a variety of learning spaces. The White Memorial Chemistry Library and the Engineering and Physics Library (EPSL) merged to form the STEM library. Besides, STEM students do not have enough quiet and comfortable space to study. There is no doubt that an undisturbed and comfortable learning environment can improve students' concentration and study efficiency. Especially for STEM students, there is an urgent need for a quiet and comfortable learning environment. To solve the problem, this article provides a solution which creates a quiet and comfortable learning environment by soundproofing walls and converting group study rooms into individual study rooms without potential disturb, the method enables staffs and students to eliminate the interference and focus on their work in the library.
\end{abstract}

\section{Introduction}

According to the survey and its feedback from students in STEM math and other majors, more than $95 \%$ of STEM-major students liked to go to the library to solve problems in the quiet environment. However, about $60 \%$ of the students was unavailable to stay in a quiet and comfortable place in the library due to various factors such as scheduled course, which may reduce their learning efficiency.

Located in the math building, STEM library is the best way to deal the above dilemma. However, in the STEM library, there is a multifunctional room on the first floor and a group study area on the second floor, thus making the learning environment in the STEM library often not quite enough for students to concentrate on math and other issues. After a detailed understanding of the library structure and a comprehensive investigation, the author found that there were only a few large study rooms in the STEM library, and if students want to use the rooms, the minimum number for booking is three.

Every study room in large libraries like the McKeldin Library or Jollifu Library is occupied during peak periods. The study rooms are overcrowded and none of them is available.. It happens every day in this library. The phenomenon indicates that a quiet place to study is in urgent need. According to Library Association survey, the University of Maryland ranked the 64th for material expenditure from 2016 to 2019, exceeding our peer schools that were mostly in the top 25. Though the utilization rate of the library has exceeded $65 \%$, the effective utilization rate is far from satisfactory. The survey data shows that the daily occupancy rate is only $45 \%$. The reason for this phenomenon is that the majority of students make use of the study room in the same period of time while other schools perform well in library regional division and reasonable spatial distribution. To keep pace with excellent school libraries, The STEM library needs to carry out some measures to improve the utilization rate of study rooms and achieve better service effects.

\section{Analysis of the influence of personal learning environment on learning efficiency}

Recent years have witnessed that STEM majors have increasingly been popular in the job market. But in fact, many STEM undergraduates transfer to non-STEM majors every year. According to data from the National Education Statistics Center of the Ministry of Education, 52\% of mathematics students chose to transfer their majors and eventually took other courses during 2011 and 2016. One 
of the reasons given by the students who gave up studying mathematics is that math is a challenging subject and it's difficult for them to maintain enthusiasm.

The research surveys demonstrate that a quiet and independent learning environment can improve students' concentration. Without disturbance, students can keep a highly concentrated state and attain new knowledge efficiently. Compared with students studying in a quiet environment, other students spend a longer time digesting new knowledge. In other words, a good personal learning environment plays a significant role in mathematics and other STEM fields. Mathematics students need to concentrate when they want to learn more and more abstract concepts and formulas, they need. The same is true for other STEM students. They take similar courses, and some even have to take higher-level math courses and computer courses to meet their professional requirements. Therefore, for most STEM students, a quiet learning environment is crucial.

Through further research, the author found that the quality of the environment not only influenced the mood of the students but also directly determined the efficiency and effect of learning. By in-depth analysis of sampling surveys and inquiries among some mathematics students, the author obtained some environmental factors affecting the learning efficiency.

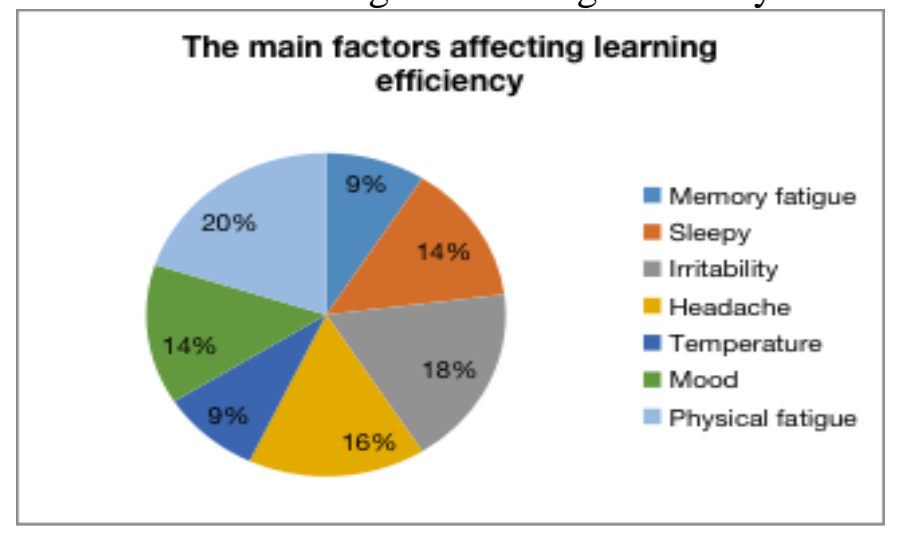

Figure 1 The main factors affecting learning efficiency

As shown in the Figure 1, the environmental factors of impacting on learning efficiency mainly include memory fatigue, drowsiness, irritability, headache, temperature, emotion, and physical fatigue. The data shows that $70 \%$ of students believe that the learning environment has an impact on their learning efficiency and effect, while the remaining 30\% students state that the environment does not affect their learning efficiency. This demonstrates that the majority of students consider that the environment plays one of the vital roles in learning.

\section{How to improve the learning environment of STEM libraries}

\subsection{To establish a personal study room to transform the learning environment}

Through the above investigation and analysis, the author believe there is an urgent need to improve the STEM library. The first method is to establish a separate study room. However, there is not enough space to add a new study room. Improving the space utilization on the second floor is another choice. However, it is impossible to remove the collective rooms, because the organizations of the University will carry out activities in these places. What's more, there are many bookcases left on the second floor. It is better to keep this room as a study room. The third method is to improve the area on the third floor. The group study rooms on the third floor are never fully occupied at the same time, and there is vacant space for group study around the study rooms. Therefore, the most appropriate way is to change the group study room into individual study rooms.

At present, the STEM library is divided into many areas. These areas have different functions, but they are all for group or collaborative activities, such as multifunctional rooms, research shared rooms, group study rooms, and group study areas. However, it is noteworthy that there are few places for individual study. As mentioned above in this article, individual study is an important part of the learning program. Although STEM students have many group projects, they still need to study 
individually to work on their own parts. The new individual study room can improve the efficiency and concentration of their study.

To maximize cost-effectiveness, the best strategy is to convert the existing group study rooms into individual study rooms. There are four group study rooms on the third floor of the STEM library, including two larger study rooms and two smaller study rooms. It is feasible to convert two of them into separated study rooms. Each large group study room can be turned into at least three separate study rooms, as it can fit two tables, ten chairs, and a blackboard. The smaller group study room can be turned into two separate study rooms. . Separating these study rooms by soundproofing walls is not only cheaper than rebuilding study rooms, but also quitter than previous learning environment.

\subsection{To create a diversified personal study room}

\subsubsection{To strengthen the construction of modern facilities}

Beside humanized management, the library needs modern equipment, such as some projectors or large teaching screens to introduce information and communication in the library. It is necessary to set up some printers so that students can print the materials they need in time. Of course, students must pay for the service. Furthermore, setting up some network query functions, such as the interconnection of mobile apps, the library will make it convenient for students to query the books they need or query their questions from the Internet. Meanwhile, the library should also install independent surveillance equipment cameras, which can enhance the safety of library management and facilitate the management of personnel who use the study room.

\subsubsection{To establish specialized service personnel}

In addition to the provision of hardware facilities, library service needs to be improved. Library needs hire volunteers at the beginning of the operation. The volunteers mainly introduce the functions of the personal study room to students who use the study room for the first time and provide auxiliary data query function. If students need to take a large-scale examination or need to produce works for a certain subject, the guide can help make a literature retrieval table for students to read.

\subsubsection{To setting up a high-level individual study room}

The establishment of individual study rooms is not only significant for students but also helpful for faculties, because they often need independent space to. set up such a study room with professional equipment, such as a multimedia room equipped with some professional projection or shooting equipment. It can be set to charge on time, open flexibly, and exclusively for experts and scholars, thus may attract high-level talents. The study rooms will not only enhance the visibility of the library but also provide a convenient place for experts and scholars.

\section{Advantages of setting up a personal study room}

\subsection{Personal promotion}

On the one hand, the establishment of a personal study room can improve the construction of spiritual civilization. Some people think that the personal study room is dispensable. They consider collective environment as well as appropriate atmosphere are more helpful to study. However, the library neglected to construct the individual study rooms. A personal study room can increase the utilization rate of the overall space of the library and provide a space for those students who need independent thinking. At the same time, the construction of individual study rooms can attract more students to study. This will in turn, improve the learning environment of the university.

On the other hand, the establishment of a personal study room can strengthen the connection between students and the library. In the public learning area, particular services and activities are not available, because conversation or activity may affect people who are working in the same space. The library can regularly carry out some activities of personal contact, provide consultation and tutor services, and conduct some survey in time. Through such activities, the library will strengthen its relationship with the community. 


\subsection{Improvement of library management functions}

Individual study rooms are indeed popular in universities and setting up a single study room in the STEM library can alleviate the lack of the study area which is quiet. Furthermore, the STEM department can make better use of the space on the third floor for students who are used to work on group projects on the first or second floor. The current design increases the density of personnel and also increases the utilization rate of the library. Therefore, converting the group library into a single study room will not only cause little waste of space but also provide individuals with a quiet and comfortable space.

Additionally, a separate study room can reduce noise and ensure the discipline of the library. Students can talk about their course topics, practice the presentation, and work on their group projects together but not distract others. This can alleviate the pressure of library administrators who are used to keep order in the library and prevent students from disturbing others.

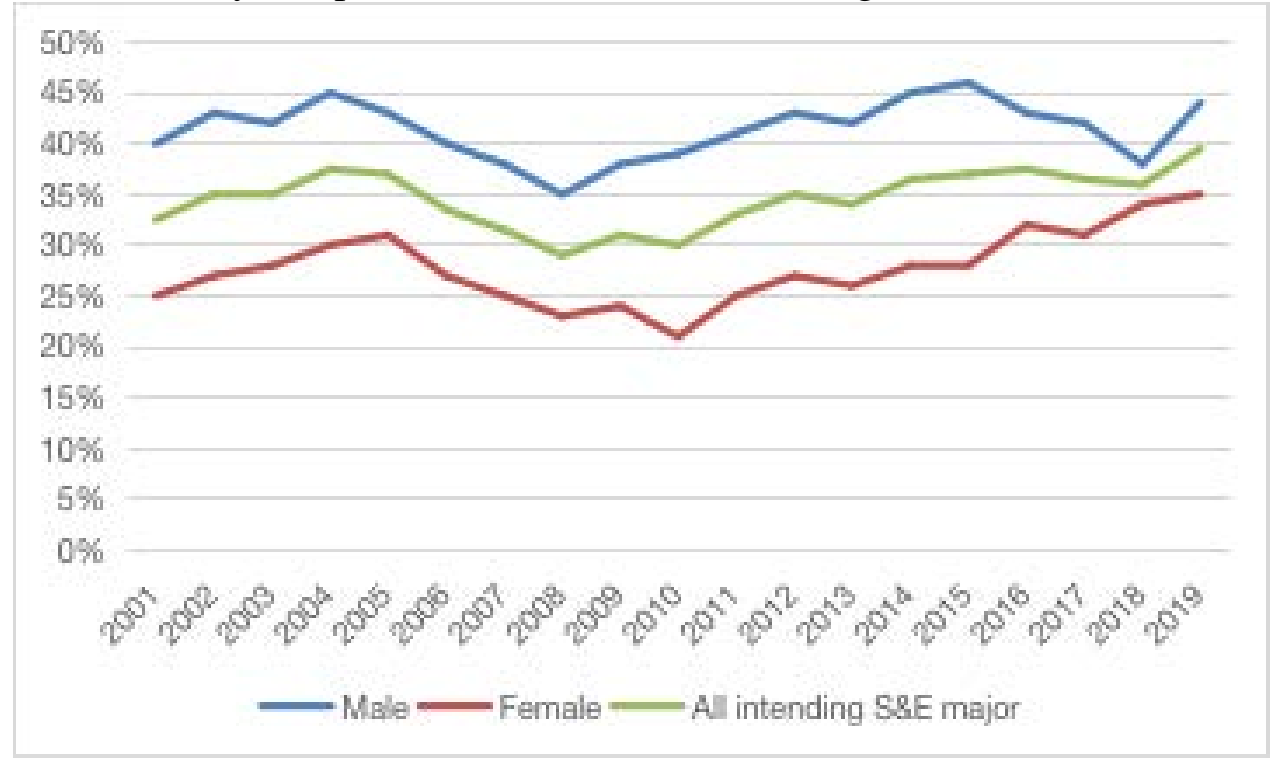

Figure 2 The influence of libraries on STEM majors in the past 20 years

For the STEM department, the individual study room increases the quality of learning places in the STEM library and that can be good attraction for potential freshmen. As shown in Figure 2, about $40 \%$ of STEM students complain that the quality of the library affecting their professional study. The proportion of women enrolling STEM will likely increase because women are more sensitive to the learning environment. It will directly determine whether they will choose a more difficult STEM major. The library is a very important way for college students to obtain resources independently. Some college students who want to study STEM-related fields but have not yet decided to enroll are more likely to take the personal study room into consideration. Therefore, adding individual study rooms will increase the number of people who choose STEM majors.

\section{Feasibility study of project implementation}

\subsection{Technical feasibility}

In order to convert group collective study rooms into single study rooms, the library should soundproof walls between each room if economic conditions are available.

In 2011, South Korea invented an assembled wall, which is classified as a 'movable non-load-bearing partition'. The wall is easy to move and install. After years of tests and trials, the author has proposed a method to improve the sound insulation of such walls.

(1) The wall should contain board members, which are separated from other board members and form at least one layer.

(2) The bolt members are alternately placed on different inner surface of the plate members and include a web plate on which holes of multiple diameters are formed. 
(3) The insulating material is inserted in the space between the plate and the students.

(4) There is at least one damper on the surface of the insulating member and the falling block composed of the second hole.

\subsection{Economic feasibility}

After conducting research and calculation, the author finds that the price of this kind of separation wall in the technical part is within budget which comes from the STEM department. Library budgets need to be obtained from key levels, published on the campus newspaper Rattlesnake in 2016. It pointed out that the university administrators cut the budget of the university library system. Now it is a great opportunity for school to increase in the library budget, because many students expressed dissatisfaction with the budget cuts in that article and the school wants to solve the complaints.

Investing in decoration of the study room has immeasurable value and effect. The study rooms can provide a quiet and comfortable learning environment for students to study, arousing more students to learn, and raising their enthusiasm and efficiency in such study rooms. In addition, generally speaking, a number of alumni or external entrepreneurs will provide financial assistance for the modification of the study room. In this case, the school doesn't need to bear too much pressure on the expenses.

\subsection{Legal feasibility}

All projects must be implemented within a legal scope. Therefore, based on the literature review, the article draw the following legal conclusions.

(1) Safety: The inventor of the wall mentioned in this article emphasized that the wall has sound insulation and fireproof functions. If the library uses such sound insulation materials, the safety is beyond doubt.

(2) Privacy: Each study room can protect the privacy of students well, because there is only one person in each room, and students have enough freedom to study in their favorite way.

(3) Patent: The wall mentioned in this article has a patent belonging to the applicant, but our STEM department can look for alternative products, or contact the inventor for more information.

\section{Conclusion and prospect}

This article has made a constructive exploration of transforming the STEM library into study rooms. Firstly, the article focuses on the current research and previous cases. The author had a thorough understanding about development of the library converted into a study room. Secondly, it analyzed the influence and importance of the learning environment for students, especially for STEM students; after conducting an in-depth analysis of the methods and measures improving the learning environment of the STEM library, the author discovered the importance and advantages of establishing a personal learning space and then the author made the feasibility study of the scheme which transforms STEM library into study rooms from three aspects that are technology, economy and law. Finally, the article concluded that this scheme is very feasible and can produce many beneficial effects.

At present, the university recommends that students should study in a non-interference environment because interference such as smart phones and man-made noise will greatly reduce the student's learning efficiency. Equipped with the individual study rooms, the library will offer students a quiet learning environment, which will not produce interference, noise, human interference, etc. For STEM students, a quiet place is very significant because they always work on complex thinking tasks. For example, students majoring in mathematics must handle numerous math homework problems, and the students majoring in engineering frequently use programming software to make models.

Moreover, the 2017 Huffington Post article Why silence is so good for your brain confirmed that a quiet environment can indeed help people relieve stress and replenish their source of intelligence. The conclusion of this article from the university's research is that the brain can "recover limited cognitive resources in an environment where our sensory input is below normal." In quiet conditions, the 
restoration process and the individual learning process can occur at the same time, which helps to improve students' learning efficiency and durability.

The book Strategic Management of Intellectual Capital pointed out that personal learning was essential to organizational learning. Consisted of individuals, organizational learning was closely related to individuals'. Individuals' inspiration in learning would undoubtedly make difference to organizational learning. In other word, the individual study laid a good foundation for group study. Consequently, the author can draw the conclusion that transforming the STEM library into a single study room is not only benefit for those who want to study alone, but also for students who study in groups.

\section{References}

[1] Xiaomin Yang. Measurement and evaluation of classroom environment quality in colleges and universities [D]. Hengyang; University of Nanhua, 2013

[2] Feifei Wang. Research on the Factors Affecting Students'Learning Efficiency[R].

[3] Daniel, HK. (2016). The Link between Individual and Organizational Learning. In KLEIN, D. A (Eds), Strategic, management of intellectual capital(pp.41-62).

[4] Gregoire, C. (January 9, 2017). Why Silence Is So Good for Your Brain. Huffington Post. Retrieved June 20, 2019.

[5] Nam, J., Jung, S., Kim, J., \& Kang, H. (April 12,2012). US8820476B2 - Assembly wall body having improved sound absorbing and screening performance and an assembly structure comprising the same. Retrieved July 1, 2019.

[6] National Center for Education Statistics (NCES). (2017). Percentage of 2011-12 First Time Postsecondary Students Who Had Ever Declared a Major in an Associate's or Bachelor's Degree Program Within 3 Years of Enrollment, by Type of Degree Program and Control of First Institution: 2014. Institute of Education Sciences, U.S. Department of Education. Washington, DC.

[7] Shaneka, M., \& Gary, R. (2019). ARL Statistics 2016-2017. Washington DC: Association of Research Libraries. Doi: https://doi.org/10.29242/stats.2016-2017.

[8] Mengwei Cai, Xiaocai Huang, Lin Xie, et al. The impact of college classroom environment on learning efficiency[J]. Educational Abstracts 2014.

[9] Admin, D. (2016, August 12). Editorial - Library budget needs rescuing from critical levels. The Diamondback. Retrieved July 1, 2019.

[10] Association of Research Libraries. (2019). ARL statistics 2016-2017 (G. Roebuck \& S. Morris, Eds.). Washington, D.C.: Association of Research Libraries. Retrieved July 1, 2019.

[11] Cowell, J. (2017, August 06). Silence: Should Librarians Apologize for providing quiet? A Medium Corporation. Retrieved July 1, 2019.

[12] Daniel, H.K. (2016). The Link between Individual and Organizational Learning. In KLEIN, D. A (Eds), Strategic management of intellectual capital (pp.41-62).

[13] Gregoire, C. (2017, January 09). Why Silence Is So Good for Your Brain. Huffington Post. Retrieved June 20, 2019.

[14] Millar, J., Oliner, S., \& Siche, D. (2016). Time-to-plan lags for commercial construction projects. Regional Science and Urban Economics.

[15] Nam, J., Jung, S., Kim, J., \& Kang, H. (2010, April 12). US8820476B2 - Assembly wall body having improved sound absorbing and screening performance and an assembly structure comprising the same. Retrieved July 1, 2019.

[16] National Center for Education Statistics (NCES). (2017). Percentage of 2011-12 First Time Postsecondary Students Who Had Ever Declared a Major in an Associate's or Bachelor's Degree Program Within 3 Years of Enrollment, by Type of Degree Program and Control of First Institution: 2014. Institute of Education Sciences, U.S. Department of Education. Washington, DC.

[17] National Science Foundation. (2012). What percentage of freshmen intend to major in an S\&E field when they start college? (n. d.). Retrieved June 30, 2019.

[18] Realtor University. (2015, April 07). How Your Study Environment Affects Productivity. 